\title{
Research on optimization method of primary frequency modulation capability based on different ratios of hydropower
}

\author{
Xiaojie Pan ${ }^{1}$, Maosen Fan ${ }^{2 *}$, Wenchao Zhang ${ }^{2}$, Liwei Zhang ${ }^{2}$, and Xing Chen ${ }^{2}$ \\ ${ }^{1}$ Central China Branch of State Grid Corporation, Wuhan, Hubei Province, 430077, China \\ ${ }^{2}$ Beijing Kedong Electric Power Control System Co., Ltd., Beijing, Beijing, 100089, China
}

\begin{abstract}
With the continuous development of China's cross-regional interconnected power grid, largecapacity and long-distance transmission have become an important feature of China's power grid. As the transmission capacity of single-return transmission lines continues to increase, the risk of frequency fluctuations increases, making grid operation scheduling more concerned with the performance of the unit's primary frequency modulation. This paper tests the frequency stability of a power system under different scenarios, in which the proportion of water and thermal power in the system is different. The results represent that a system with a large proportion of hydropower has poorer frequency stability. This paper offers a method of primary frequency modulation, which proposed to improve the frequency stability of the system by increasing the time delay of the hydropower unit's governor. The results of simulation prove that this method is an available solution to solve the problem of poor system frequency stability when a system has a high ratio of hydropower.
\end{abstract}

\section{Introduction}

Frequency is one of the important indicators to measure the power quality of the power system. The primary frequency modulation of generator groups is an important method to maintain the system frequency stability after a fault, which causes a lot of power loss, and to prevent the system frequency from fluctuating greatly under normal load fluctuations [1-2]. With the development of renewable energy, the participation of multiple power sources in primary frequency modulation has become a hot topic. [3] describes the current evaluation system for the performance of primary frequency regulation of generators, and analyses the frequency regulation action of grid-connected generators. Based on the analysis of the principle of primary frequency regulation and the generator group's response, it summarizes the important indicators that can reflect the capability of primary frequency modulation and several methods for evaluating the performance of primary frequency modulation. The frequency dividing system proposed in [4] automatically determines the active power output of the wind power, energy storage, and thermal power, which improves the reaction speed and quality of system frequency modulation. [5] introduces the existing types of wind turbines and the impacts on the system frequency after wind turbines connected to the grid. It also explains the basic principles and characteristics of the existing wind turbine frequency modulation control strategy and describes the coordinated frequency control system between wind energy, hydro energy, thermal power and load. At the same time, the participation of wind power in frequency modulation may bring about a secondary drop in frequency. Using energy storage to assist power system frequency is a very promising method for frequency modulation [6-14]. However, energy storage devices cost a lot, but the conversion rate is relatively lower than other methods. It is always been more economical to improve frequency stability by optimizing the traditional power supply governors.

Since province Sichuan, Tibet, Yunnan in China are rich in hydropower, the construction and commission of large hydropower stations, pumped storage power stations develop rapidly. The long-distance transmission lines in these regions make the interconnection of China's power grid complex. This situation caused the safety problems of the power system are more relative to the control strategy of hydropower stations and pumped storage power stations [15]. When a large power fluctuation occurs in a grid with a high hydropower ratio, the balance of the active power will be further destroyed due to the water hammer effect of hydraulic turbines, which eventually leads to the deterioration of the grid frequency [16-18]. It is urgent to find a way to solve the problem of frequency deterioration caused by a high proportion of hydropower.

Based on the frequency response of the system under different scenarios, this paper analyses the influence of water hammer on frequency stability, in which hydropower and thermal power account for different

*Corresponding author's e-mail: 744757525@qq.com 
proportions in the power system. A method to improve the system frequency stability by increasing the time delay of the hydropower unit governor will be offered. This method can effectively avoid the secondary frequency drop caused by the frequency regulation of wind turbines and save the cost from using energy storage to control the system frequency. It provides a new idea for frequency-control in a system with a high ratio of hydropower.

\section{Frequency response models based on Different Proportions of Hydrothermal Power in a System}

\subsection{Frequency response model}

The unbalanced power $\Delta \mathrm{p}$ caused by the disconnection of the transmission lines, generators and loads are usually regulated by adjusting the rotor kinetic energy $K_{\mathrm{w}}$, the effect of load frequency regulation $\Delta P_{\mathrm{L}}$, and the primary frequency regulation $\Delta P_{\mathrm{G}}$ of the generator (as in equation (1)).

$$
\Delta P=\frac{\mathrm{dW}_{\mathrm{K}}}{\mathrm{d} t}+\Delta P_{\mathrm{L}}+\Delta P_{\mathrm{G}}
$$

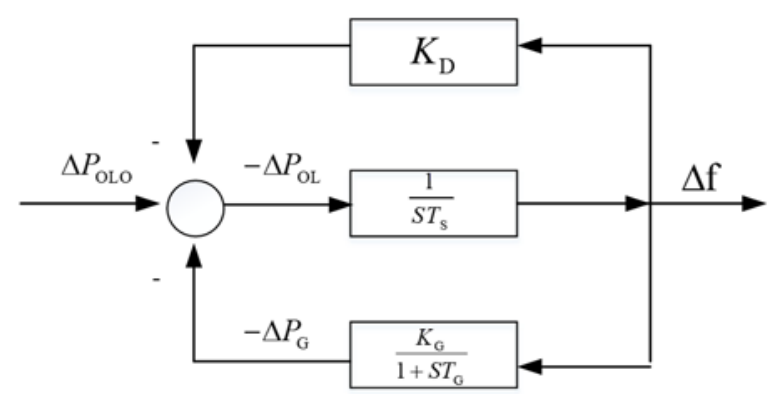

Figure 1. Block diagram of frequency response model for a single machine with load.

In the block diagram of frequency response in a traditional single-machine-load model, the forward link represents the rotor motion equation of an equivalent generator. The other two feedback links represent the frequency characteristics of the load and generator (see figure 1). The state equation of the system can be listed as equation (2):

$$
\left\{\begin{array}{l}
T_{\mathrm{S}} \frac{\mathrm{d} \Delta f}{\mathrm{~d} t}=-\Delta P_{\mathrm{OL}} \\
T_{\mathrm{G}} \frac{\mathrm{d} \Delta P_{\mathrm{G}}}{\mathrm{d} t}+\Delta P_{\mathrm{G}}=-K_{\mathrm{G}} \Delta f \\
\Delta P_{\mathrm{D}}=K_{\mathrm{D}} \Delta f \\
\Delta P_{\mathrm{OL}}=\Delta P_{\mathrm{D}}-\Delta P_{\mathrm{G}}+\Delta P_{\mathrm{OLO}}
\end{array}\right.
$$

In the equation (2), $K_{\mathrm{D}}$ is the load frequency regulation coefficient, $T_{\mathrm{S}}$ is the inertia time constant of the equivalent machine, $K_{\mathrm{G}}$ is the frequency response characteristic of a generator, $T_{\mathrm{G}}$ is the integrated time constant of the generator's governor and prime mover, $\Delta \mathrm{f}$ is the frequency deviation, $\Delta P_{\mathrm{OL}}$ is the amount of power deficit, including load and generating units, $\Delta P_{\mathrm{D}}$ is the effect of the load frequency adjustment, $\Delta P_{\mathrm{OLO}}$ is the size of the power deficit caused by the fault.

The feedback link of the frequency adjustment characteristics of the generator can be refined and divided into the prime mover + governor feedback link of the thermal power unit and the prime mover and governor feedback link of the hydropower unit (see figure 2). The governor links of thermal power units and hydropower units can be expressed by the frequency response characteristic coefficient of the generator and the first-order inertia link. The prime mover links of hydropower units and thermal power units are introduced in the next sections.

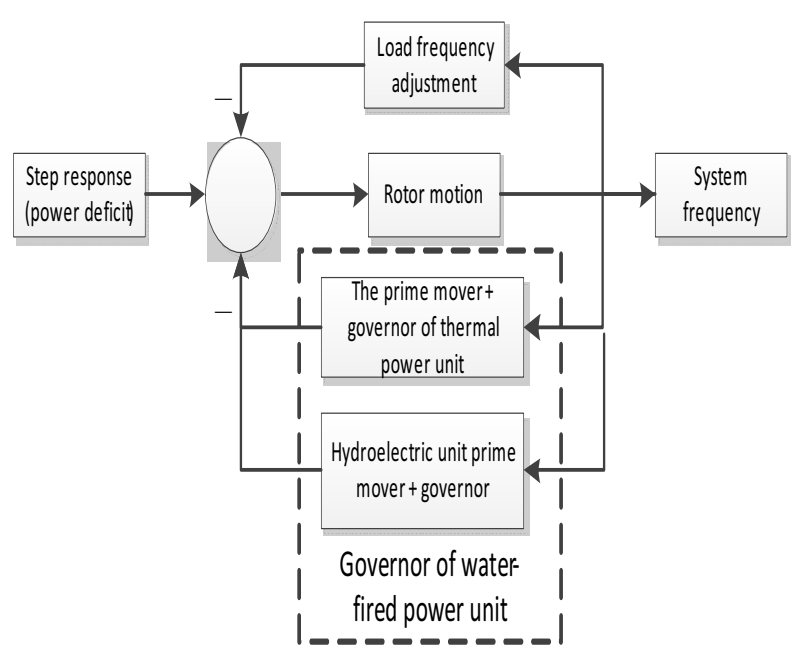

Figure 2. Frequency Response Model Considering Different Proportions of Hydrothermal Power.

\subsection{Turbine Model considered Water Hammer Effect}

Turbines turned by falling water to generate electricity. In order to build a model for researching the dynamic characteristics of a turbine, the water hammer effect must be considered, which the transient process is caused by the inertia of the water flow in the turbine and diversion pipeline. When there is a power loss in a system, the wicket gates suddenly open. Because of the inertia of the water flow, the instantaneous power input increased, thus deteriorate the frequency. 
The water hammer effect makes the control of the turbine's mechanical input complicated. The dynamic process can be described by a function of the mechanical power and the opening of a valve (as in equation (3)). The time constant of the water hammer effect varies from $0.5 \mathrm{~s}$ to $5 \mathrm{~s}$. The frequency dynamic process depends on the value of water hammer effect's time constant. When the value of the water hammer effect constant is large, the frequency during the dynamic process will be worse.

$$
P_{\mathrm{M}}=\frac{1-S T_{\mathrm{W}}}{1+0.5 S T_{\mathrm{W}}} u_{\mathrm{w}}
$$

In equation (3), $P_{\mathrm{M}}$ is the mechanical input of the generator, $u_{\mathrm{w}}$ represents the valve opening of a turbine; $T_{\mathrm{W}}$ is the water hammer effect time constant.

\subsection{A Prime Mover Model considered Volume Effect for thermal generators}

The main method to change the output power of a steam turbine is to adjust the valve opening. There is a certain space between the steam valve and the steam nozzle, namely the steam dome volume. When the valve opening of the steam turbine changes, the steam pressure cannot change immediately thus the power output of the steam turbine remains. That means the change of the output lags behind the change of valve opening. The steam volume effect can be described mathematically by a firstorder inertial element. The steam volume effect of a small-capacity steam turbine can be ignored because the space between the steam valve and the nozzle is small. In contrast, the steam volume effect of large-capacity steam turbines is quite significant and must be considered.

The relationship between the mechanical input and Steam valve opening of a thermal power unit can be simplified described as follows:

$$
P_{\mathrm{M}}=\frac{1}{1+S T_{C H}}\left(\alpha+\frac{1-\alpha}{1+S T_{R H}}\right) \mu
$$

$P_{\mathrm{M}}$ is the mechanical input power of the generator, $\mu_{\text {is the valve opening of a thermal turbine, }} T_{\mathrm{CH}}$ is the time constant of the high-pressure cylinder, $T_{\mathrm{RH}}$ is the time constant of the medium-pressure cylinder, $\alpha$ is the proportion of the capacity of the high-pressure cylinder.



Figure 3. Transfer Function Block Diagram of Steam Turbine.
The block diagram of the overall control strategy is shown as figure 4:

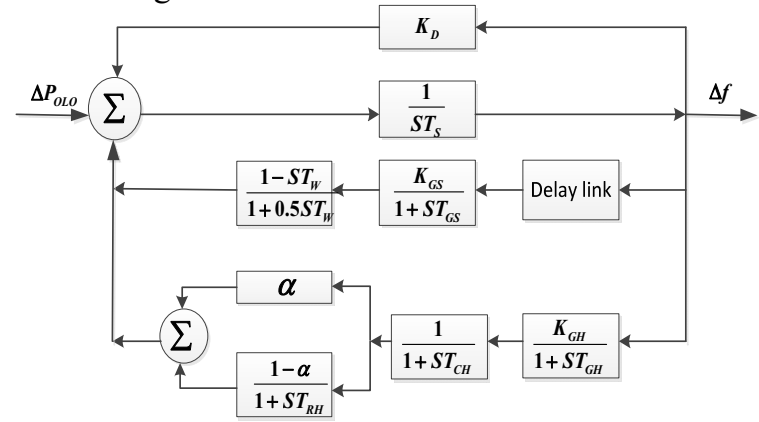

Figure 4. Detailed Frequency Response Model Considering Different Proportions of Hydrothermal Power.

$K_{\mathrm{GS}}$ is the frequency response characteristic of the steam turbine, $T_{\mathrm{GS}}$ is the integrated time constant of the governor of the turbine, $T_{\mathrm{GH}}$ is the integrated time constant of the governor of the steam turbine.

\subsection{Output Analysis of hydro and thermal power units}

The curves in figure 5 represent the power output characteristics of the thermal power unit and hydropower unit after a disturbance, which caused a $20 \%$ power shortage. Due to the water hammer effect, the output of the hydro turbine showed a certain degree of power inversion in the early stage. On another side, the mechanical output of the thermal power unit increases relative slower, because of the volume effect.

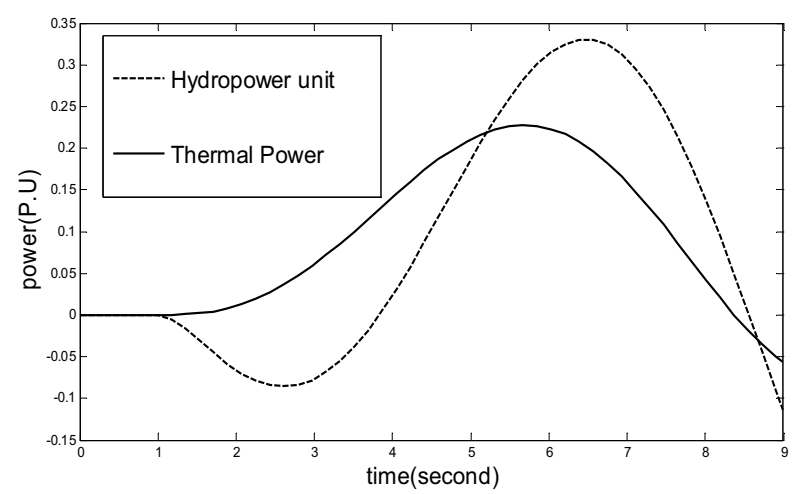

Figure 5. Output Curves of Hydropower and Thermal Power Units after Failure.

\section{Analysis of Frequency Characteristics in a System with different Proportions of Hydro and thermal power}

Generally, the value of $\mathrm{KG}$ of the turbo-generator is between 16.7 and 25, the value for hydro-generator is $25 \sim 50$. The proportion of hydro- and thermal power in a system can be definite by changing the value of KG. The formula for defining the proportion of the hydro- and thermal power unit is as follows: 


$$
\left\{\begin{array}{l}
\eta_{H}=\frac{P_{H}}{P_{B}} \\
\eta_{S}=\frac{P_{\mathrm{S}}}{P_{B}}
\end{array}\right.
$$

$\eta_{\mathrm{H}}$ is the proportion of thermal power, $\eta_{\mathrm{S}}$ is the proportion of hydropower, $P_{\mathrm{H}}$ is the sum of the power generation of thermal power units in the system, $P_{\mathrm{S}}$ is the sum of the power generation of hydropower units in the system, $P_{\mathrm{B}}$ is the sum of the power generation of thermal power units and hydropower units in the system.

Suppose that the initial system with the frequency response characteristic coefficient $\mathrm{KG}$ of hydropower and thermal power unit are both 25 , and $60 \%$ power comes from the remote DC power supply. To simulate a system with $50 \%$ thermal power $+50 \%$ hydropower, the KG of thermal power and hydropower are settled as 5 . To simulate $100 \%$ thermal power, set the KG thermal power of 10 and the hydropower $\mathrm{KG}$ of 0 . The remaining parameter will be settled as the water hammer effect time constant is $2 \mathrm{~s}$, the volume effect time constant is $1.5 \mathrm{~s}$, the high pressure cylinder ratio is 0.5 , the load power factor is 1.0 , and the system equivalent inertia time constant is $8 \mathrm{~s}$. The power loss will be settled as $10 \%$ of system active power. By adjusting the proportion of water and thermal power in a system, the table of system lowest frequency and the frequency curve shown in table 1 and figure 6 are obtained.

Table 1. $10 \%$ power gap disturbance, minimum frequency table of the system with different hydropower units.

\begin{tabular}{cccccc}
\hline $\begin{array}{c}\text { Proportion of } \\
\text { hydropower } \\
\eta\end{array}$ & $0 \%$ & $25 \%$ & $50 \%$ & $75 \%$ & $100 \%$ \\
units & & & & & \\
\hline $\begin{array}{c}\text { Lowest } \\
\text { frequency } \\
(\mathrm{Hz})\end{array}$ & 48.9 & 48.65 & 48.5 & 47.5 & 46.5 \\
\hline
\end{tabular}

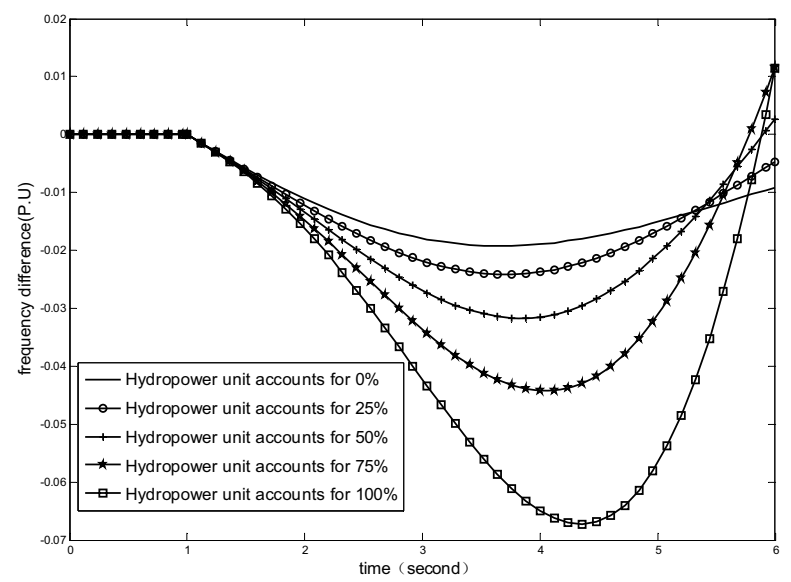

Figure 6. Frequency curves under the scenarios with different hydropower and thermal power ratios.
Due to the water hammer effect, the hydropower unit cannot provide effective active power support for the system at the early stage of the dynamic process after a disturbance, especially when a system has a higher rate of hydropower. Figure 6 shows obviously that in a hydropower-majority system, the value of frequency drops significantly at the beginning of the dynamic process after a disturbance.

\section{Optimization Method for primary frequency modulation of the hydroelectric power system}

\subsection{Maximum Frequency Drop Duration and its Impact Factors}

$T_{\mathrm{f}}=\frac{T_{S}}{k_{\mathrm{D}}}$ is the time constant of system frequency drop,

$K_{\mathrm{S}}=K_{\mathrm{D}}+K_{\mathrm{G}}$ is the factor to reflect the adjusting effect on the power frequency of the entire system, Which can be solved by equation (2):

$$
\Delta f(t)=-\frac{\Delta P_{o L O}}{K_{\mathrm{S}}}\left[1-2 \mathrm{~A}_{\mathrm{m}} \mathrm{e}^{-\alpha \mathrm{t}} \cos (\Omega t+\phi)\right]
$$

In the formula, $\alpha=\frac{1}{2}\left(\frac{1}{T_{\mathrm{G}}}+\frac{1}{T_{\mathrm{f}}}\right)$ is the time constant of frequency change, $\Omega=\left(\frac{K_{\mathrm{S}}}{\mathrm{T}_{\mathrm{S}} \mathrm{T}_{\mathrm{G}}}-\alpha^{2}\right)^{\frac{1}{2}}$ is the angular velocity of frequency oscillation , $\mathrm{A}_{\mathrm{m}}=\frac{1}{2 \Omega T_{S}} \sqrt{K_{\mathrm{S}} K_{G}}$ is the amplitude of frequency oscillation, $\phi=\arctan \left(\frac{1}{\Omega}\left(\frac{K_{\mathrm{S}}}{T_{\mathrm{S}}}-\alpha\right)\right)$ is the angle of frequency oscillation.

Therefore, when considering the influence of the speed regulation system of the generation units, the dynamic process of system frequency in a singlemachine model can be represented by a curve whose amplitude decays with the time constant $\alpha^{-1}$, and the maximum rate of decline appears at the beginning of the disturbance $\left.\frac{\mathrm{d} f}{\mathrm{~d} t}\right|_{\max }=-\frac{\Delta P_{\mathrm{OLO}}}{T_{\mathrm{S}}} ;$ the frequency drop is $\Delta f_{\infty}=\frac{\Delta P_{\mathrm{OL} 0}}{K_{\mathrm{S}}}$; the frequency deviation reaches the maximum when

$$
t_{m}=\frac{1}{\Omega} \arctan \left(\frac{2 T_{\mathrm{S}} T_{G} \Omega}{K_{\mathrm{D}} T_{G}-T_{S}}\right)
$$


It can be seen from the above equation (7) that the lowest frequency appearance timing is related to the factors, such as inertial time constant of the equivalent machine, the integrated time constant of the generator's governor and prime mover, and the power system frequency adjustment effect coefficient of the entire system, but the amount of power shortage caused by disturbance is not related. The duration of the water hammer effect and the appearance of the lowest point of the frequency are irrelevant to the power deficit of the system. The optimized frequency control method can be found by analyzing the relationship between the duration of the water hammer effect and the appearance of the lowest frequency.

\subsection{Time Analysis of Water Hammer Effect of Hydropower Unit}

Figure 7 shows the mechanical power characteristic of the hydropower unit after a fault that caused a system power shortage. Generally, the reverse adjustment phenomenon of output power caused by the water hammer effect occurs at the beginning of the mechanical power change of the hydropower unit. The turbine's output curve can be regarded as a concave zone and the convex zone. In the concave zone, the output of the hydropower unit decreases and makes a negative contribution to the system frequency. In the convex region, the hydropower unit makes a positive contribution to the system frequency.

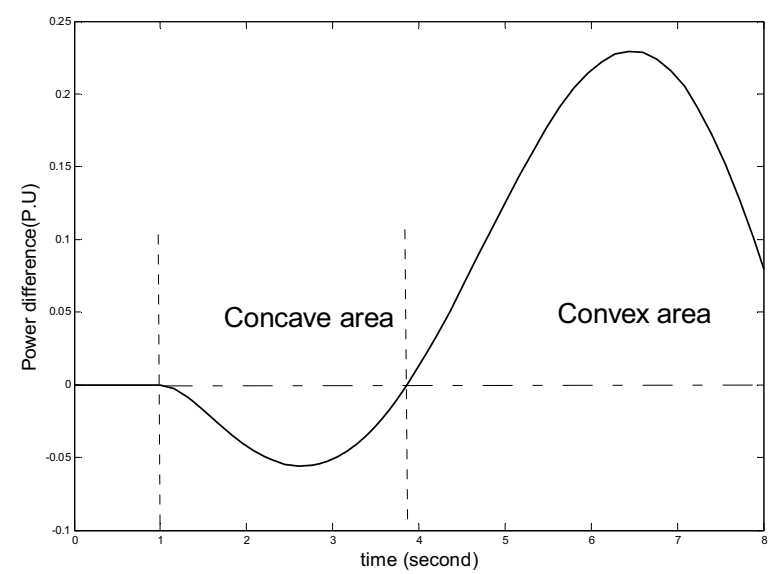

Figure 7. Output Curve of Hydroelectric Units.

The comparison between the curve of hydropower plant mechanical input and the curve of system frequency shows, that when a system has a small water hammer effect time constant, the lowest frequency appears after the end of the water hammer effect. In contrast, the lowest frequency appears before the end of the water hammer effect when the value of water hammer effect time constant is large. When the ending of the water hammer effect occurs earlier than the appearance of the lowest frequency, a time delay of starting the hydropower unit's governor can reduce the negative impact on system frequency in the concave area. Figure 8 shows that when the water hammer effect time constant is $1 \mathrm{~s}$, the lowest frequency time of the system lags behind the water hammer effect's end time. Figure 9 shows that when the water hammer effect time constant is $5 \mathrm{~s}$, the lowest frequency time of the system leads the end time of the water hammer effect.

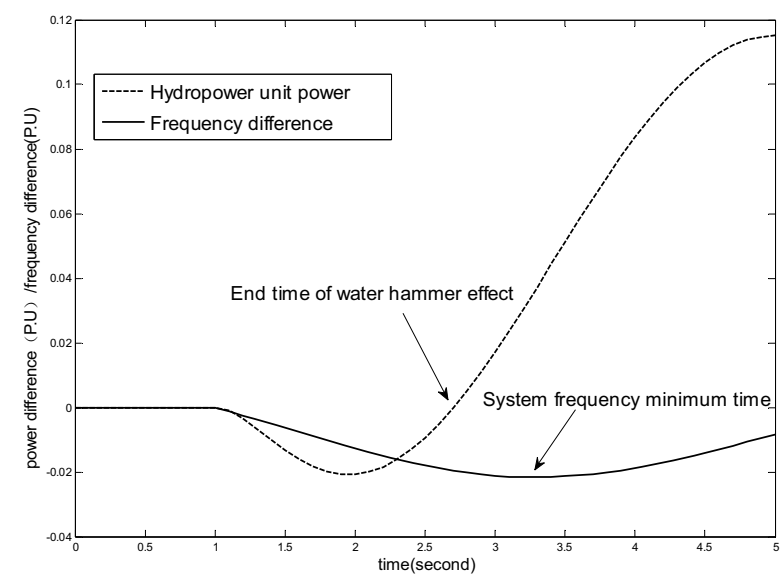

Figure 8. Comparisons between frequency and output of hydropower units when the time constant of water hammer effect is $1 \mathrm{~s}$.

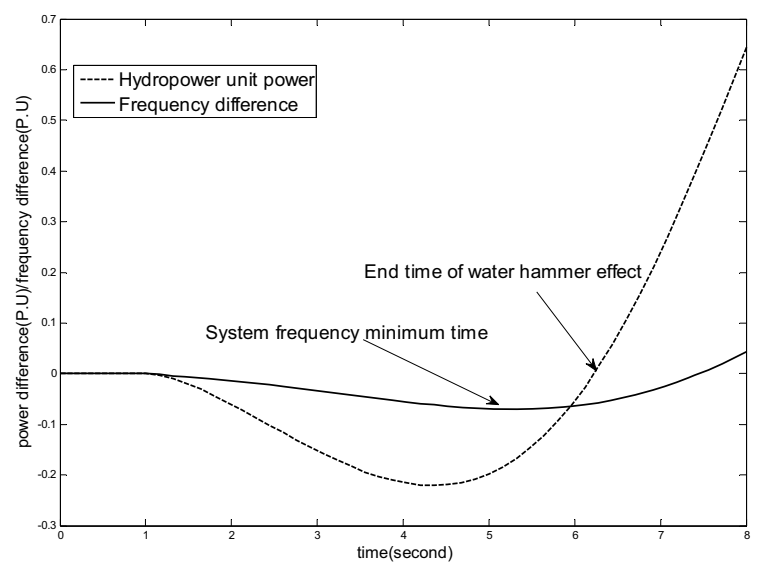

Figure 9. Comparing the frequency with the output of hydropower units when the time constant of water hammer effect is $5 \mathrm{~s}$.

\subsection{Analysis of Simulation Results}

Set a disturbance that causes a $10 \%$ power shortage in a system, which the system has $50 \%$ hydropower. The water hammer effect time constant of $1 \mathrm{~s}, 2 \mathrm{~s}$, and $3 \mathrm{~s}$ will be simulated.

The research shows, that when the value of water hammer effect time constant large, the ending of the water hammer effect lags behind the occurrence moment of the lowest frequency. By increasing the time-delay of the hydropower unit governor, the value of minimum frequency after a fault can be significantly improved and its timing of appearance will be delayed. This phenomenon can be interpreted as, that when the value of the time constant of the water hammer effect is large, the lowest frequency appears in the concave region of the water hammer effect and the system frequency experiences negative growth during this process. The tiny time delay gains more time for more control measures for the frequency. However, the method of 
increasing the delay of the hydro unit's governor also causes a slower recovery of system frequency under certain circumstances.

Table 2 Frequency table of the system when the time constant of water hammer effect is $1 \mathrm{~s}$.

\begin{tabular}{cccccc}
\hline $\begin{array}{c}\text { Hydroelectric } \\
\text { generator } \\
\text { governor delay (s) }\end{array}$ & 0 & 0.25 & 0.5 & 0.75 & 1. \\
\hline $\begin{array}{c}\text { The lowest } \\
\text { frequency of the } \\
\text { system (Hz) }\end{array}$ & 48.83 & 48.75 & 48.70 & 48.65 & 48.62 \\
\hline
\end{tabular}

Table 3 Frequency table of the system when the time constant of water hammer effect is $2 \mathrm{~s}$.

\begin{tabular}{cccccc}
\hline $\begin{array}{c}\text { Hydroelectric } \\
\text { generator } \\
\text { governor delay (s) }\end{array}$ & 0 & 0.25 & 0.5 & 0.75 & 1. \\
\hline $\begin{array}{c}\text { The lowest } \\
\text { frequency of the } \\
\text { system (Hz) }\end{array}$ & 48.24 & 48.21 & 48.21 & 48.22 & 48.25 \\
\hline
\end{tabular}

Table 4 Frequency table of the system with a time constant of water hammer effect of $3 \mathrm{~s}$.

\begin{tabular}{cccccc}
\multicolumn{5}{c}{ water hammer effect of $3 \mathrm{~s}}$. \\
\hline $\begin{array}{c}\text { Hydroelectric } \\
\text { generator governor } \\
\text { delay (s) }\end{array}$ & 0 & 0.25 & 0.5 & 0.75 & 1. \\
\hline $\begin{array}{c}\text { The lowest } \\
\text { frequency of the } \\
\text { system (Hz) }\end{array}$ & 47.54 & 47.63 & 47.73 & 47.89 & 47.98 \\
\hline
\end{tabular}

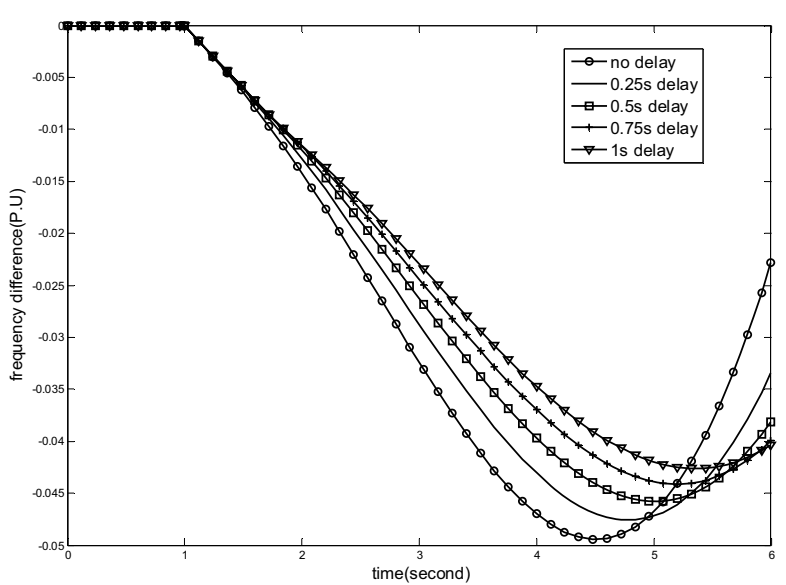

Figure 10. When the water hammer effect is $3 \mathrm{~s}$, the hydroturbine with different delay frequency curves.

The method of increasing the governor's time delay is not appropriate to the system with a small value of the water hammer effect time constant, because the lowest frequency appears in the convex area of the turbine's mechanical power curve, the increasing mechanical power has an active influence on frequency recovery. The delayed turbine governor's action may even cause frequency deterioration.

Whether a setting of time-delay is added to the turbine governor module during the frequency adjustment process, and how long the delay will be settled, are depending on the appearance of the lowest frequency, the end time of the water hammer effect and the specific requirements for frequency stability of an actual system. The model mentioned in this article is relatively simple and can only be used for qualitative analysis. The specific optimal time-delay should be analysed and considered according to the actual system.

\section{Conclusions}

Based on the analysis of the water hammer effect of hydro-power units and the volume effect of the steam turbine unit, this paper builds a dynamic model that can reflect the frequency characteristics of different systems with different proportions of hydropower and thermal power and analyzes the dynamic process of the system frequency. By analyzing the hydro unit's output curve during the process of water hammer effect and the appearance of the lowest frequency, this article proposed a method to improve the primary frequency modulation capability of the power grid with a high proportion of hydropower, by increasing the time delay of the hydropower unit's governor. The results of simulation prove that the proposed method can improve the minimum frequency of the system after a fault, and the appearance of the minimum frequency will be delayed accordingly, thus gains time for other frequency control operations.

\section{References}

1. Wei, D., Tian. L., Qiao, H., et al. (2017) Calculating the thermal storage coefficient of thermal power unit boilers by primary frequency modulation disturbance. J. Sci. China Electric Power, 50: 71-76.

2. Li, Z., Wu, X., Zhuang, K., et al. (2017) "9.19" Jinsu DC bipolar blocking accident frequency characteristics analysis and reflection. J. Sci. Power system automation, 41: 149-155.

3. Wu, X., Li, Z., Jiang, W., et al. (2018) Review of primary frequency modulation performance evaluation methods for grid-connected generators. J. Sci. Electronic Design Engineering, 6: 177-183.

4. Qu, T., Su, X., Yan, X., et al. (2018) Frequency modulation strategy for wind, storage and fire based on frequency division principle and regional control. J. Sci. Electrical measurement and instrumentation, 55: 128-135+153.

5. Zhang, X., Chen, Y., Yue, S., et al. (2018) Wind Power Participation in Power System Frequency Modulation Technology. J. Sci. Power Grid Technology, 42: 1793-1803.

6. Li, X., Huang, J., Chen, Y., et al. (2016) A review of large-scale energy storage power supply participation in power grid frequency modulation. J. Sci. Power system protection and control, 44: 145153.

7. Mercier, P., Cherkaoui, R., Oudalov, A.. (2009) Optimizing a Battery Energy Storage System for Frequency Control Application in an Isolated Power System. J. Sci. IEEE Transactions on Power Systems, 24:1469-1477. 
8. Li, J., Yang, S., Gao, K.. (2015) Large-scale energy storage system assists frequency modulation technology analysis of conventional units. J. Sci. Power construction, 36: 105-110.

9. Stroe, D. I., Knap, V., Swierczynski, M., et al. (2016) Operation of Grid-Connected Lithium-Ion Battery Energy Storage System for Primary Frequency Regulation: A Battery Lifetime Perspective. J. Sci. IEEE Transactions on Industry Applications, 99:1-1.

10. Li, J., Feng, X., Yan, G., et al. (2018) Review of power system frequency modulation under high wind power permeability. J. Sci. Power system protection and control, 2: 163-170.

11. Xu, J., Tang, X., Xu, Q., et al. (2018) Frequency control considering deep and fast load-changing capability of thermal power units. J. Sci. Power system automation, 42: 51-56.

12. Wang, W., Li, Y., Cao, J., et al. (2018) Control strategy of multi-terminal DC virtual synchronous machine based on virtual governor. J. Sci. (2018) China Journal of Electrical Engineering, 38:12.
13. Xue, Y., Tai, N., Liu, L., et al. (2009) A New Method of Doubly Fed Wind Turbine Participating in System Frequency Regulation. J. Sci. High Voltage Technology, 35: 2839-2845.

14. Liu, J., Yao, W., Wen, J., et al. (2014) Technical prospects for large-scale wind power participation in system frequency adjustment. J. Sci. Power grid technology, 38: 638-646.

15. He, Y., Guan, L., Cai, Q., et al. (2004) Analysis of Security Function and Benefit of Pumped Storage Power Station in Power Grid. J. Sci. Power Grid Technology, 28: 54-57.

16. Hu, Y., Wang, X., Teng, Y., et al. (2017) Frequency stability control strategy for multi-terminal voltage source DC interconnected system. J. Sci. Power system automation, 41: 51-57.

17. Wang, F., Liu, J., Han, F., et al. (2017) Application of DC modulation to improve AC network operation characteristics of hydropower energy base. J. Sci. Power grid technology, 12: 187-192. 